\title{
Obstructive sleep apnea syndrome and obesity: screening ability
}

\author{
Tomoyuki Kawada $^{1}$
}

Received: 4 September 2019 /Revised: 23 September 2019 / Accepted: 7 November 2019 / Published online: 27 November 2019

(C) Springer Nature Switzerland AG 2019

Dear Editor,

I read with interest a paper by Unal et al., who investigated the predictive ability of obesity indices for obstructive sleep apnea syndrome (OSAS) [1]. Waist-to-height ratio, waist circumference, and body mass index (BMI) were selected for the analysis. The authors presented cutoff values of each obesity index for OSAS and also for severe OSAS, stratified by sex. I have some concerns about their study.

First, the authors adopted a receiver-operating characteristic (ROC) curve analysis to specify screening ability. Although the cutoff values for detecting patients with OSAS and with severe OSAS were presented, there was no information of statistical superiority among the three obesity indices for screening OSAS. I recommend the authors conduct statistical comparisons among the three obesity indices to specify superiority for detecting OSAS $[2,3]$. One may check $\mathrm{R}$ software for supporting mutual statistical comparison of the area under the curve (AUC) of each ROC curve. Statistical software such as STATA ${ }^{\circledR}$ and Medcalc $®$ can be used to compare AUCs.

Second, there was a sex difference in obesity indices for prediction ability of OSAS, and screening ability of obesity indices for OSAS was suspected to be higher in females. In general, the prevalence of OSAS is higher in men than women, and there is a difference of fat distribution by sex [4]. Regarding sex differences, alcohol intake and other lifestyle factors should be included as independent variables for adjustment in the analysis. As ROC curve analysis is a univariate procedure, propensity-matching ROC curve analysis can adjust several confounding variables.

Finally, there are ethnic differences in obesity indices [5] and caution should be paid regarding the cutoff values to be used in specific populations.

\section{Compliance with ethical standards}

Conflict of interest The author declares that there are no conflicts of interest.

\section{References}

1. Unal Y, Ozturk DA, Tosun K, Kutlu G (2019) Association between obstructive sleep apnea syndrome and waist-to-height ratio. Sleep Breath 23(2):523-529

2. Hanley JA, McNeil BJ (1983) A method of comparing the areas under receiver operating characteristic curves derived from the same cases. Radiology 148(3):839-843

3. McNeil BJ, Hanley JA, Funkenstein HH, Wallman J (1983) Paired receiver operating characteristic curves and the effect of history on radiographic interpretation. CT of the head as a case study. Radiology 149(1):75-77

4. Bredella MA (2017) Sex differences in body composition. Adv Exp Med Biol 1043:9-27

5. Stryjecki C, Alyass A, Meyre D (2018) Ethnic and population differences in the genetic predisposition to human obesity. Obes Rev 19(1):62-80

Publisher's note Springer Nature remains neutral with regard to jurisdictional claims in published maps and institutional affiliations.
Tomoyuki Kawada

kawada@nms.ac.jp

1 Department of Hygiene and Public Health, Nippon Medical School, 1-1-5 Sendagi, Bunkyo-Ku, Tokyo 113-8602, Japan 